\title{
Osteoid osteoma of the ribs-Is image intensifier or bone scintigraphy a mandatory diagnostic tool-A case report with Review of literature
}

\author{
Suraj Wasudeo Nagre* and Saptarshi Paul \\ Department of CVTS, Grant Medical College, India
}

\begin{abstract}
Osteoid osteoma $(\mathrm{OO})$ is a benign osteogenic tumour first reported by Jaffe in 1935 . OOs may affect any bone, but more than half of the tumors occur in the long bones of the lower extremities. The frequency of OOs affecting the ribs is extremely low (1-1.4\%), with only 14 reported cases with surgical intervention to date. Complete surgical excision is the standard treatment method for osteoid osteoma and is usually offered to patients experiencing chronic and substantial pain that is not relieved by conservative treatment. In this report we present a case of osteoid osteoma of the posterior part of the shaft of the sixth rib affecting a 30 -year-old male, who had presented with symptoms of severe pain over the affected area and underwent surgical resection. Excised rib segment showed no osteosclerotic lesion on $\mathrm{X}$ ray so immediately extended resection of sixth rib was done. Here we have tried to evaluate the importance of the presence of the skeletal scintigraphy or $\mathrm{C}$ Arm image intensifier intra operatively by comparing our experience with the available literature.
\end{abstract}

\section{Introduction}

Osteoid osteoma is a type of benign bone tumor, which was first described by Jaffe in 1935 [1]. It is a rare condition, which accounts for only $3 \%$ of primary bone tumors. Individuals aged between 5 and 24 years old are the most commonly affected [2]. The main symptom of the disease is pain that worsens at night, which may be alleviated by NSAIDs (non-steroidal anti-inflammatory drugs). Current treatment modalities include surgical excision, as well as less invasive techniques. After treatment, symptoms can be controlled. The most commonly affected sites are the long bones of the lower extremities and the patient outcome is good [3].

\section{Case report}

A 30-year-old male complained of nocturnal pain in his left posterior chest which had persisted for 2 years. Conservative treatment was performed for a period of 12 months with administration of NSAIDs at a nearby hospital. His symptoms were refractory to medication. Therefore, he was referred to our hospital for further treatment. At the initial visit to our hospital, there was no local tenderness, swelling, or redness, but the patient complained of severe pain over the left side of the back, inferior to the left scapula. A plain radiograph showed mild bone sclerosis of the posterior part of the left 6 th rib. CT examinations revealed a small $(6 \times 6 \mathrm{~mm})$ well demarcated osteosclerotic lesion in the posterior end of the left $6^{\text {th }}$ rib; minimal periosteal reaction was noted along the rib (Figure 1). No centrally calcified nidus was noted. Pre-operative suspicion was strongly of that of an osteoid osteoma. The patient was taken up for surgery and under GA through posterior minithoracotomy posterior segment of sixth rib was excised (Figure 2a).

The excised portion of the $6^{\text {th }}$ rib was sent for $\mathrm{X}$ ray, however no osteosclerotic lesion was present in that (Figure 3a). So immediately extended resection involving the $6^{\text {th }}$ and $7^{\text {th }}$ ribs was done. The resected $7^{\text {th }}$ rib showed the osteosclerotic lesion this time on $\mathrm{X}$ ray (Figure $3 \mathrm{~b}$ ).
Incision closed in layers after keeping negative suction drain (Figure 2b). Patient extubated and shifted to ward.The resected bone segments of both sixth and seventh rib externally looked same (Figure $4 \mathrm{a}$ and $4 \mathrm{~b}$ ) so we sent them for histopathological examination.

Post operatively patient was comfortable. Chest $\mathrm{X}$ ray done and compared with preopt Chest X ray (Figure 5a and 5b). Drain removed after 48 hours and patient was discharged on fifth postopt day.Stich removal was done on fiftinth postopt day .

Histopathological examination of sixth rib was normal but seventh rib revealed the presence of osteoid tissue in a background stroma of fibrovascular tissue and thin trabeculae inter-anastomosing with a single layer of osteoblasts (Figure 6).

\section{Discussion}

OO is a benign osteogenic tumour first reported by Jaffe [1] in 1935. OOs may affect any bone, but more than half of the tumours occur in the long bones of the lower extremities. The frequency of OOs affecting the ribs is extremely low (1-1.4\%), with only 14 reported cases with surgical intervention to date [3-16]. Our case had presented itself at an age which is beyond the normal age group of incidence [3]. Osteoid osteomas are characterized by a well-demarcated core with a typical size of $<1 \mathrm{~cm}$ and by a distinctive surrounding zone of reactive bone formation [3]. The defining symptom of osteoid osteoma is pain during the night that responds to nonsteroidal anti-inflammatory

Correspondence to: Suraj Wasudeo Nagre, Department of CVTS, Grant Medical College, India, Tel: 09967795303; Email: surajnagre@yahoo.com

Key words: osteoid osteoma, rib, image intensifier

Received: February 14, 2018; Accepted: February 24, 2018; Published: February 28,2018 

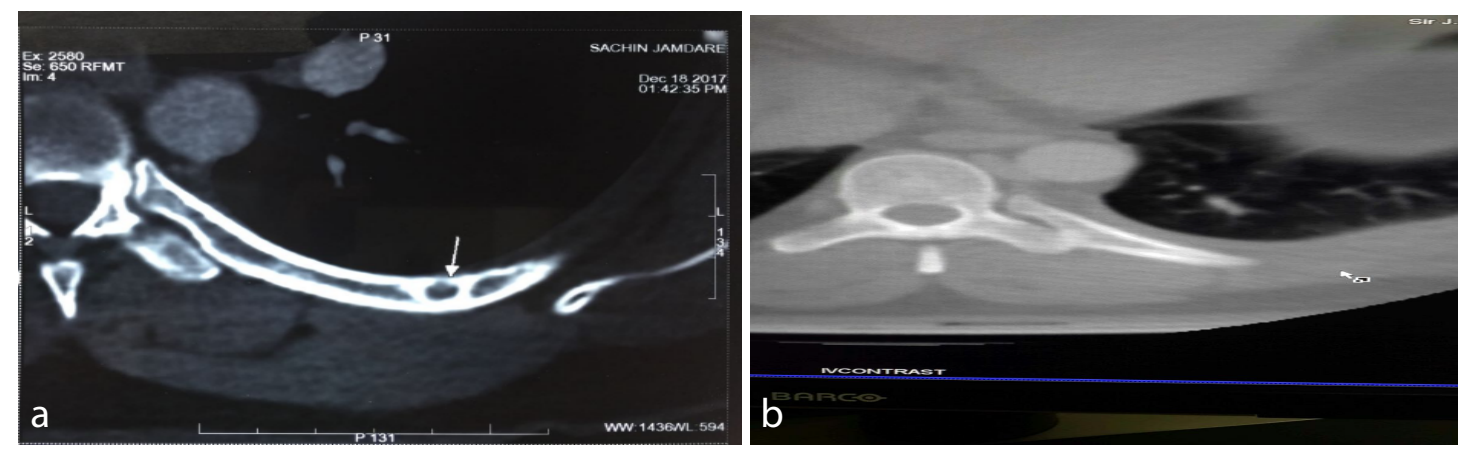

Figure 1. a) Small $(6 \times 6 \mathrm{~mm})$ well demarcated osteosclerotic lesion in the posterior end of the left $6^{\text {th }}$ rib in propt CT scan b) Post opt CT scan.
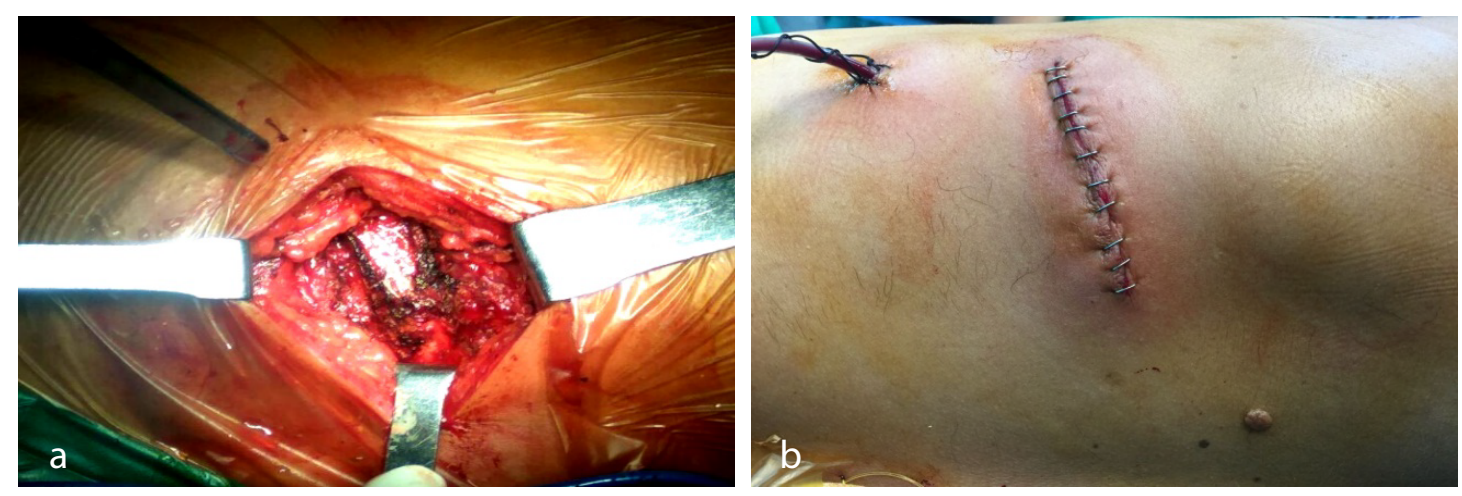

Figure 2. a) Intra Operative sixth rib, b) After closure of incision.
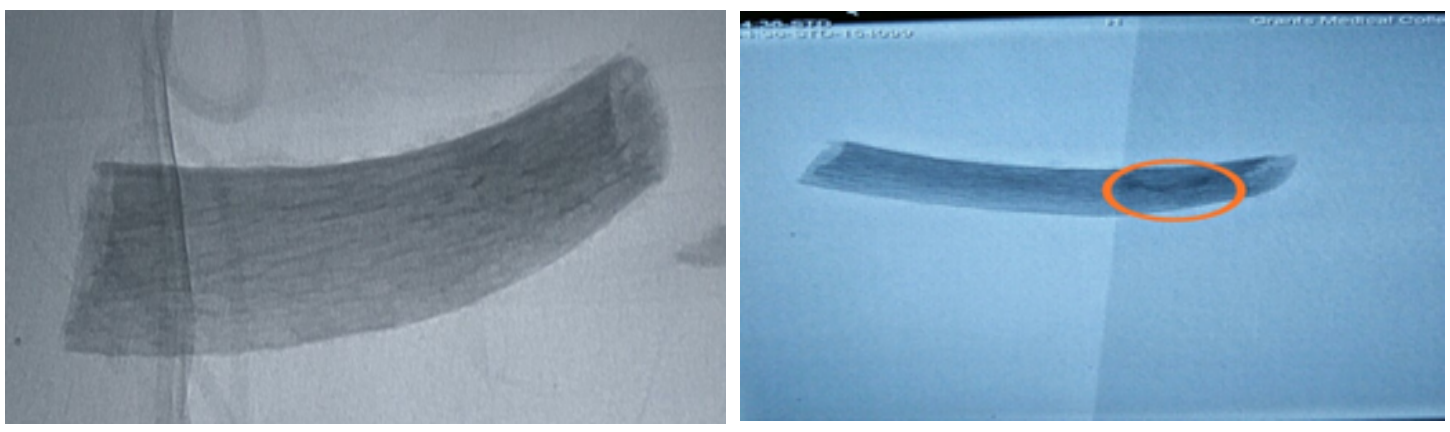

Figure 3. a) No osteosclerotic lesion 6 rib b) Osteosclerotic lesion seen 7 rib.
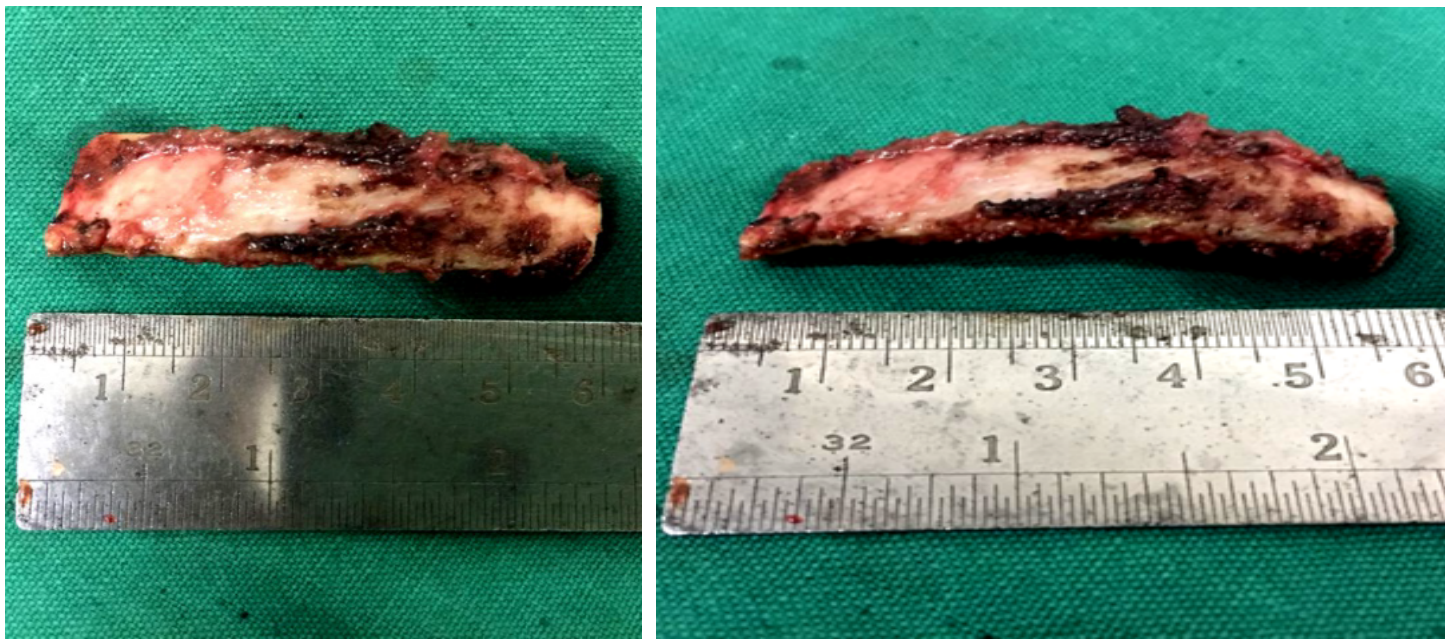

Figure 4. Resected rib segments a) Sixth rib b) Seventh rib. 


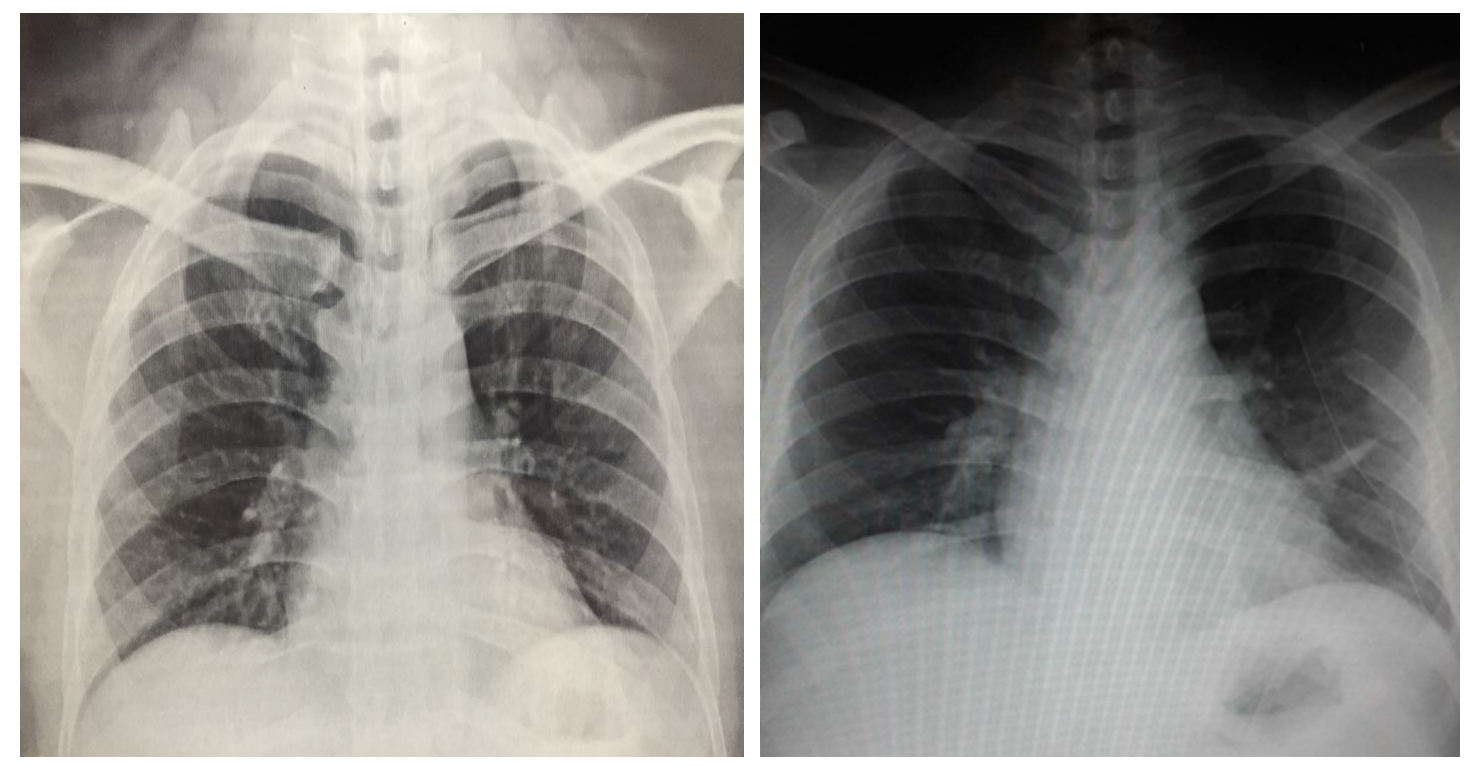

Figure 5. Chest X ray a) Preopt b) Postopt.
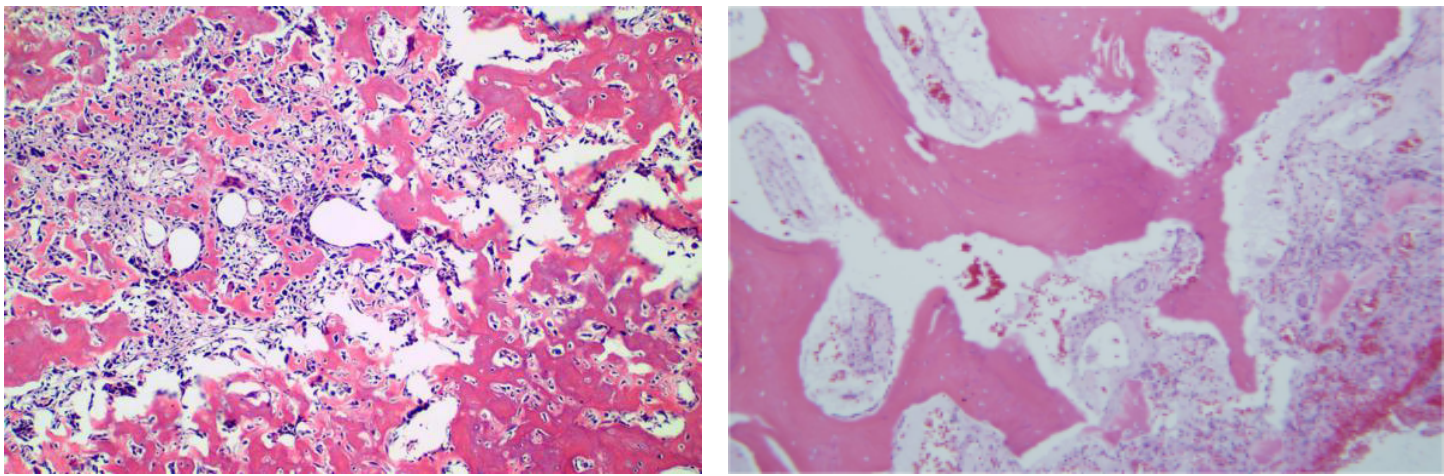

Figure 6. Histopath seventh rib under low and high power

drugs and salicylates. The lesions most commonly involve the posterior or posterolateral shaft of the rib and, upon imaging, present with similar features to tumours located elsewhere in the body. Imaging typically reveals a small radiolucent lesion with a thick sclerotic margin of reactive bone. Due its accuracy in detecting the nidus, CT is the preferred imaging technique used for the assessment of osteoid osteomas $[3,7,15,18]$. When the osteoid osteoma occurs in the posterior portion of the rib near the spine, it may lead to scoliosis [19]

Both conservative and operative techniques have been reported for the treatment of OO. Conservative treatment consists of NSAID administration for a prolonged period of time, which reportedly leads to alleviation of pain in select cases. The common principle for operative treatment of $\mathrm{OO}$ is thorough resection of the nidus, but incomplete resection could lead to local recurrence ${ }^{[20]}$. Although the ribs are easily accessed, the reported lengths of en bloc resection of the nidus ranged from 5 to $9.5 \mathrm{~cm}$, which is significantly wider than the size of the nidus, that have led to varying reports of functional impairments [3,5-7]. Klonecke et al. [20] reported that intraoperative scanning has evolved because of the excessively wide excision necessary in the past that had to be planned to help guarantee complete removal of the lesion. Here we shall discuss about the importance of the image intensifier or skeletal scintigraphy in accurately localising the lesion and leading to minimal excision, instead of a wide local excision.
As per the available literature of the 15 cases of rib osteomas reported so far, we have come to the following consensus [3-16] as in Table 1.

As per the above Table 1, a total of 8 authors used bone scintigraphy; of which Pirayesh et al. [16] used bone scintigraphy pre, intra as well as post operatively [16]. A total of 3 authors used both intra operative $\mathrm{C}$ arm image intensifier as well as pre-operative skeletal scintigraphy $[3,4,8]$. C arm was used by 3 authors, but that was always in combination with the skeletal scintigraphy $[3,4,12]$. No localizing diagnostic modality was used by 3 authors $[8,15]$. Pre-operative CT imaging was used by all authors [3-16]. No data was available in case of 4 reports $[5,9,11,13]$. In the case reported by Veluvolu et al. [7], CT scan had missed the lesion pre-operatively [7], that later had to be confirmed by scintigraphy.

The limited data available online shows that preoperative skeletal scintigraphy, first described in 1980 by Rinsky et al. [17], is the most relied modality of investigation that authors worldwide have resorted to in order to localize the nidus, and accordingly reduce the amount of material resected. Although some authors have reported the importance of CT scan as being the preferred imaging modality $[3,7,15,18]$, yet there has been a single instance in which the lesion has been missed entirely by CT scan [7]. Intra operative C arm image intensifier was always used in combination with pre-operative skeletal 
Table 1. Comparision of various modalities used by surgeon.

\begin{tabular}{|c|c|c|c|c|c|}
\hline Year of study & Authors & Scintigraphy & C arm image intensifier & CT Scan & No used (C arm/scintigraphy) \\
\hline 2018 & Nagre [19] & - & - & - & No data \\
\hline 2015 & Deng et al. [3] & Yes & Yes & Yes & - \\
\hline 1983 & Kehl et al. [4] & Yes & Yes & Yes & - \\
\hline 1984 & McGuire et al. [5] & - & - & Yes & - \\
\hline 1988 & Mehdian et al. [6] & Yes & No & Yes & - \\
\hline 1992 & Veluvolu et al. [7] & Yes & No & Yes & - \\
\hline 1958 & Mauer et al. [8] & - & - & Yes & Yes \\
\hline 1986 & Lynch et al. [9] & - & - & Yes & - \\
\hline 1987 & Nelson et al. [10] & Yes & - & Yes & - \\
\hline 1989 & Kozlowski et al. [11] & - & - & Yes & - \\
\hline 1991 & Cossetto et al. [12] & Yes & Yes & Yes & - \\
\hline 1993 & Hoeffel et al. [13] & - & - & Yes & - \\
\hline 1996 & McDermott et al. [14] & Yes & - & Yes & - \\
\hline 1996 & Kargar et al. [15] & - & - & Yes & - \\
\hline 2012 & Pirayesh et al. [16] & Yes & - & Yes & - \\
\hline
\end{tabular}

scintigraphy, but never in an isolated fashion $[3,4,12]$. This shows the growing reliance of authors on the efficacy of pre-operative skeletal scintigraphy, while intra operative $\mathrm{C}$ arm imaging remains as a guiding factor for surgeons inside the operating room.

As far as our case is concerned, we are in the league of 2 previous authors who have attempted to resect the lesion with the guidance of only computed tomography $[8,15]$; though we have been able to resect the tumour with negative margins, yet we had to do an extended resection, in the absence of intra operative guidance.

\section{Conclusion}

We feel that more comprehensive data regarding the efficacy and reliability of skeletal scintigraphy and intra operative $\mathrm{C}$ arm imaging needs to be published, with a comparison of both with computed tomography. This data might in future establish skeletal scintigraphy, with or without the associated intra operative $\mathrm{C}$ arm image intensifier, as the default and most preferred diagnostic modality for this rare tumour. It was always better to use these modalities intraoperatively to prevent morbidity to patient as well as to the surgeon. So our conclusion was - use any of available modality intraoperatively was compulsory.

\section{Consent}

Informed consent has been obtained

\section{Ethical approval}

All procedures performed in studies involving human participants were in accordance with the ethical standards of the institutional and/ or national research committee and with the 1964 Helsinki declaration and its later amendments or comparable ethical standards.

\section{References}

1. Jaffe HL (1935) Osteoid osteoma. A benign osteoblastic tumor composed of osteoid and atypical bone. Arch Surg 31: 709-728.

2. Unni KK (1996) Osteoid osteoma. In: Dahlin's bone tumors: general aspects and data on 1,087 cases. 5th edition. Lippincott-Raven, Philadelphia, PA, USA, pp: 121-130.

3. Deng Z, Ding YI, Hao L, Yang F, Gong L, et al. (2015) Osteoid osteoma of the rib: A report of two cases. Oncol Lett 9: 1857-1860. [Crossref]
4. Kehl DK, Alonso JE, Lovell WW (1983) Scoliosis secondary to an osteoid-osteoma of the rib. A case report. J Bone Joint Surg Am 65: 701-703. [Crossref]

5. Nagre SW, Bhosle KN, Gawali R, Ravikumar V (2017) Innovative use of contegra valved conduit in left iliocaval stent thrombosis. Indian J Thorac Cardiovasc Surg: 1-4

6. Mehdian H, Summers B, Eisenstein S (1988) Painful scoliosis secondary to an osteoid osteoma of the rib. Clin Orthop Relat Res: 273-276. [Crossref]

7. Nagre SW (2016) Hurdles for Starting Ministernotomy Aortic Valve Replacement Program. J Cardiovasc Med Cardiol 3: 035-037.

8. MAUER I (1958) Osteoid osteoma of the 12th rib; resection under local anesthesia; a case report. Mil Med 122: 194. [Crossref]

9. Nagre SW Bendre S (2016) New four patch repair [Modified Brom's] technique for supravalvular aortic stenosis. J Cardiovasc Dis Res 7: 39.

10. Nelson MC, Brower AC, Ragsdale BD (1987) Case report 448. Osteoid osteoma of left 6 th rib with inflammatory reaction in the adjacent pleura and hyperostosis of the adjacent ribs. Skeletal Radiol 16: 601-603. [Crossref]

11. Nagre SW, Bhosle KN, Bendre S Vignesh R (2017) Surgical Management of Medium to Large Size Pulmonary AV Malformations- A Case Series. J Clin Respir Dis Care 3: 129.

12. Cossetto D, Cummine J (1991) Rapidly growing twelfth rib osteoid osteoma. Aust N Z J Surg 61: 862-864. [Crossref]

13. Nagre SW (2017) Mobile Left Atrial Mass-Clot or Left Atrial Myxoma. J Cardiovasc Dis Res 8: 31-34.

14. McDermott MB, Kyriakos M, McEnery K (1996) Painless osteoid osteoma of the rib in an adult. A case report and a review of the literature. Cancer 77: 1442-1449. [Crossref]

15. Nagre SW, Nagre MS (2015) Observational Study of Surgical Closure of Ostium Primum Atrial Septal Defect in Thirty Paediatric Patients. Ann Woman Child Health 1: 1-4

16. Pirayesh E, Amoui M (2012) A rare presentation of osteoid osteoma in a rib and unexpected "double density sign": A case report and review of literature. Iran J Radiat Res 10: 197-199.

17. Nagre SW (2015) Surgical removal of embolised atrial septal defect device from pulmonary artery. J Thorac Cardiovasc Surg 150: e55-e57.

18. Touraine S, Emerich L, Bisseret D, Genah I, Parlier-Cuau C, et al. (2014) Is pain duration associated with morphologic changes of osteoid osteomas at CT? Radiology 271: 795-804. [Crossref]

19. Nagre SW, Bhosle KN, Shaikh A, Ravikumar V (2018) Pleuropulmonary blastoma-a case report and review of literature. Indian J Thorac Cardiovasc Surg 3: 72-75.

20. Mizuno S, Anazawa U, Hotta H, Asano N, Susa M, et al. (2015) A Rare Case of an Osteoid Osteoma of the Rib Treated under Computed Tomography Guidance: A Case Report and Review of the Literature. Case Rep Oncol 8: 509-514. [Crossref]

Copyright: $\odot 2018$ Nagre SW. This is an open-access article distributed under the terms of the Creative Commons Attribution License, which permits unrestricted use, distribution, and reproduction in any medium, provided the original author and source are credited. 